Original article

\title{
MOLECULAR CHARACTERISATION OF LUMPY SKIN DISEASE VIRUS AND SHEEPPOX VIRUS BASED ON P32 GENE
}

\author{
P. M. A. RASHID, M. O. BABA SHEIKH, Z. H. RAHEEM \\ \& A. S. MAROUF \\ Molecular Diagnostic Laboratory, Sulaimani Veterinary Directorate, \\ Slemani, Iraq
}

\section{Summary}

Rashid, P. M. A., M. O. Baba Sheikh, Z. H. Raheem \& A. S. Marouf, 2017. Molecular characterisation of lumpy skin disease virus and sheeppox virus based on $P 32$ gene. Bulg. J. Vet. Med., 20, No 2, 131-140.

\begin{abstract}
Lumpy skin disease virus (LSDV) and sheeppox virus (SPV) have a considerable economic impact on the cattle and small ruminant industry. They are listed in group A of contagious disease by the World Organization for Animal Health (OIE). This study addressed molecular characterisation of first LSDV outbreak and an endemic SPV in Kurdistan region of Iraq based on P32 gene. The results indicated that P32 gene can be successfully used for diagnosis of LSDV. The phylogenic and molecular analysis showed that there may be a new LSDV isolate circulating in Kurdistan which uniquely shared the same characteristic amino acid sequence with SPV and GPV, leucine at amino acid position 51 in $P 32$ gene as well as few genetically distinct SPV causing pox disease in Kurdistan sheep. This study provided sequence information of P32 gene for several LSDV isolates, which positively affects the epidemiological study of Capripoxvirus
\end{abstract}

Key words: Capripoxvirus, Iraq, LSDV, P32 gene, SPV

\section{INTRODUCTION}

Lumpy skin disease virus (LSDV), goatpox virus (GTPV) and sheeppox virus (SPPV) belong to the genus Capripoxvirus, family Poxviridae (Fauquet et al., 2005). Capripoxviruses consist of large enveloped double strand DNA. The genome is about $151 \mathrm{~kb}$. There are close genetic relations among the species of the Capripoxvirus genus. However, there are unique traits responsible for virulence and host range. This property makes LSDV a host-specific pathogen for cattle and SPPV - host-specific for sheep (El-Nahas et al., 2011).

The lumpy skin disease is severe, highly contagious, characterised by nodules in the skin and enlarged superficial lymph nodes, sometimes fatal (Davies, 1991). Sheep pox and goat pox are characterised by pyraexia and pock lesions on the skin and internal organs causing high mortality, particularly in young animals 
(Fulzele et al., 2006). The diseases have a considerable economic impact on the cattle and small ruminant industry and are listed in group A of contagious diseased by the World Organization for Animal Health (OIE) (Kitching, 2000).

LSD is endemic in the African countries and has spread into most of the Middle East countries, Asia and there is a risk of further spread into Europe (Tuppurainen \& Oura, 2012). In Iraq, LSD was recorded for the first time in the autumn of 2013, and it continues to spread to all of the Iraqi governments (Al-Salihi \& Hassan, 2015). Classically, Capripoxvirus laboratory examination includes virus isolation, fluorescent antibody test (FAT), enzyme-linked immunosorbent assay (ELISA) (Chand et al., 1994). However, the classical examinations are not readily available everywhere, and some of them have low specificity due to cross-reactions between Parapoxvirus and Capripoxvirus (Murphy et al., 1999). Currently, sensitive and specific molecular methods are used for detection of Capripoxvirus targeting the P32, GPCR and RPO30 genes (Zhou et al., 2012).

The aims of this study were the molecular characterisation of Capripoxvirus in Kurdistan region of Iraq based on P32 gene as well as to provide information on the sequence of $P 32$ gene of LSDV.

\section{MATERIALS AND METHODS}

\section{Samples}

Skin nodules were collected from 9 cows suspected of lumpy skin disease (Fig. 1). Scab samples also were obtained from 5 sheep suspected of sheep pox in various geographical regions of the Sulaimani Governorate in a period from November 2013 to December 2014. The samples were collected aseptically and transported in a cool box to the molecular diagnostic laboratory in the Sulaimani veterinary directorate.

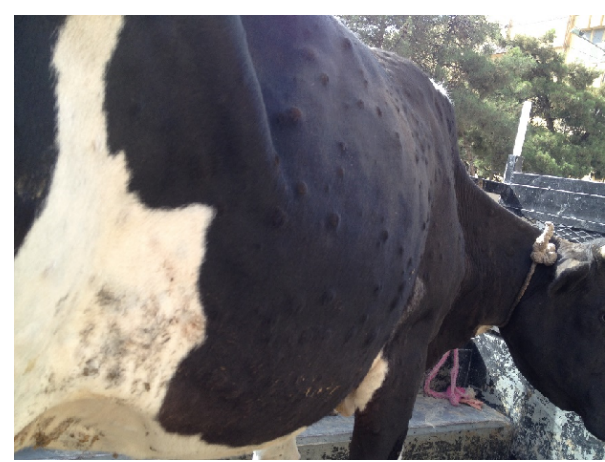

Fig. 1. Photograph of cow with severe LSD lesions in the skin.

\section{DNA extraction}

The skin samples were put in a sterile Petri dish then cut with a sterile surgical disposable blade to a smaller pieces, and pureed to become paste-like in consistency. Fifteen grammes of pureed sample were then used for DNA extraction using genomic DNA extraction kit (tissue) (Geneaid, Korea) according to the manufacturer's instructions. The purified DNAwas then stored at $-20{ }^{\circ} \mathrm{C}$ for subsequent PCR assay.

\section{PCR amplification}

The PCR amplification reaction was done according to the manufacturer instructions using Bioneer AccuPower PCR Premix. The PCR primers were designed from $P 32$ gene that is specific for the Capripoxvirus genus with the following sequence: forward primer CTAAAATTAGAGAGCT ATACTTCTT and reverse primer CGATTTCCATAAACTAAAGTA to amplify 390 bp (Heine et al., 1999). The primers were constructed by Macrogen (Korea). The PCR reaction was performed 
with $5 \mu \mathrm{L}$ of DNA template and $1 \mu \mathrm{L}$ of 10 pmol forward and reverse primers, then the reaction was made up to a final volume of $20 \mu \mathrm{L}$ with DEPC- $\mathrm{H}_{2} \mathrm{O}$. The thermal cycler (BIO-RAD, USA) parameters were: initial denaturation at $94{ }^{\circ} \mathrm{C}$ for 5 mins, 38 cycles denaturation at $94{ }^{\circ} \mathrm{C}$ for $30 \mathrm{~s}$, annealing at $50{ }^{\circ} \mathrm{C}$ for $30 \mathrm{~s}$, extension at $72{ }^{\circ} \mathrm{C}$ for $30 \mathrm{~s}$; and a final extension phase run at $72{ }^{\circ} \mathrm{C}$ for $5 \mathrm{~min}$.

\section{Electrophoresis and gel analysis}

Electrophoreses of PCR products were done in a $1.2 \%$ agarose gel. Seven $\mu \mathrm{L}$ of PCR products were stained with $3 \mu \mathrm{L}$ safe dyes then loaded on the gel and visualised by UV transilluminator and photographed (UVETIC, UK). The amplicon sizes were estimated according to the migration pattern of a 100 bp DNA ladder.

\section{Direct sequencing}

Thirty-five microliters of positive PCR products were sequenced in Macrogen sequencing service in South Korea. The identity of each nucleotide was verified twice. The coding sequences were submitted to Genbank database with accession numbers KF996498, KM047052, KM047053, KM047055, KM047056,
KM047057, KM047058, KM047059, KP313621, KP313622, KF992798, KP313623, KP313624, KP313625.

\section{Phylogenetic analysis}

Partial amino acid sequences of P32 gene of Capripoxvirus strains worldwide were obtained from the GenBank. Multiple alignments of these sequences were performed by MEGA 6 with ClustalW method (Thompson et al., 1994). MEGA 6 was used to perform phylogenetic analysis with Neighbor-Joining (NJ). The bootstrap values were determined from 1000 replicates of the original data. Sufficient detail should be provided to allow the work to be repeated.

\section{RESULTS}

\section{Capripoxvirus detection}

The partial P32 genes of Capripoxvirus were successfully amplified in all clinical samples. The expected amplicon size, 390 bp of Capripoxvirus was detected in the 9 cow samples and 5 sheep samples, the amplified fragments were confirmed by sequencing (Fig. 2).

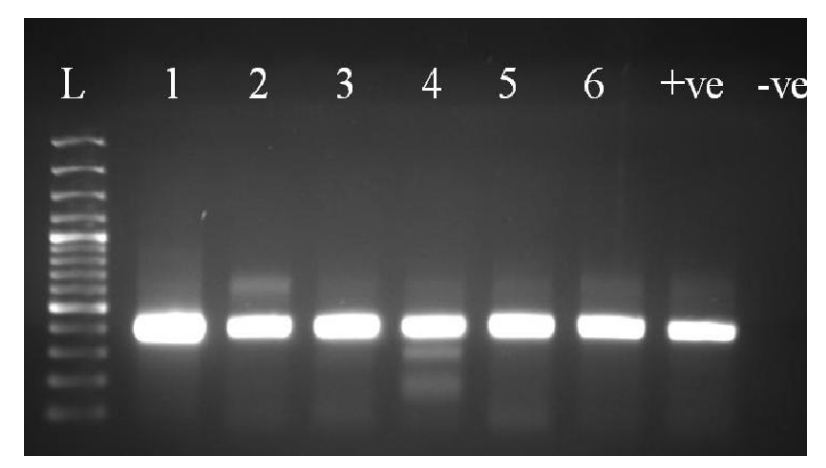

Fig. 2. Agarose gel electrophoresis pattern shows PCR amplification of $390 \mathrm{bp}$ from the $P 32$ gene of Kurdistan Capripoxvirus. Lane L: 100 bp DNA ladder, lanes 1-3: LSDV field strain, lanes 4-6: SPV field strain, lane +ve: positive control (vaccine), lane -ve: negative control. 


\section{Phylogenetic analysis}

A phylogenetic tree (Fig. 3) was constructed based on the partial protein alignment of the $P 32$ gene of Kurdistan Capripoxvirus and other Capripoxvirus published in NCBI.

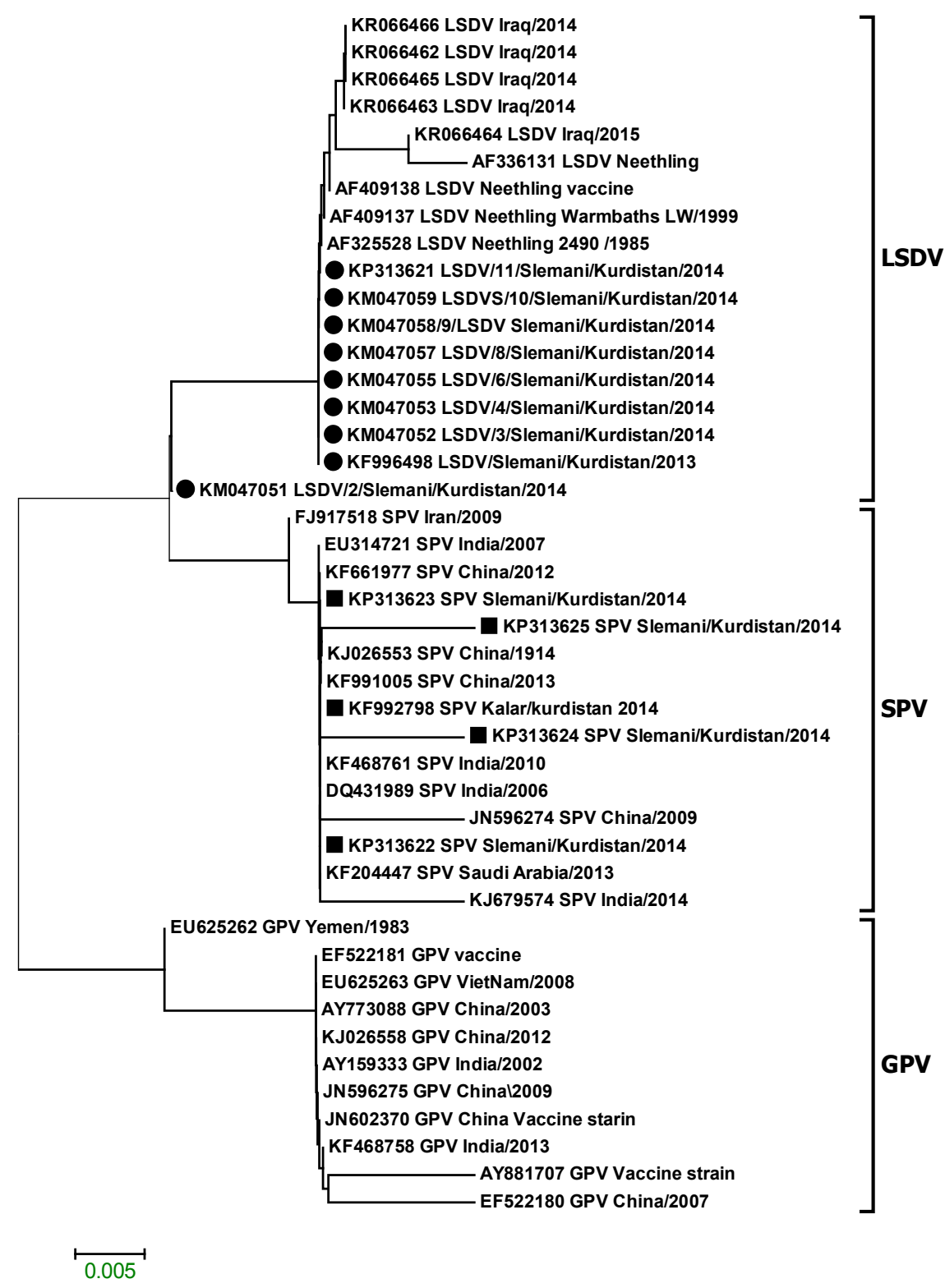

Fig. 3. Phylogenetic tree of Kurdistan Capripoxvirus isolates. Analyses of the phylogenetic tree according to partial P32 amino acid sequence indicated 3 clusters. The circles show Kurdistan/LSDV field strains and squares - Kurdistan/SPV field strains. 
The topology of the phylogenetic tree indicated three clusters; namely LSDV, GPV and SPV. All SPV strains of Kurdistan clustered in SPV lineage. The GPV was divided into two sub-clusters; one of them included only the Yemen strain (EU625262 GPV Yemen/1983), the other included GPV from China, India, and Vietnam. All Kurdistan LSDV strains in this study clustered in one lineage. KM047051 LSDV/2/Slemani/Kurdistan/ 2014 was separated from the other LSDV isolates and it formed a different subcluster.

\section{Analysis of P32 protein of Kurdistan Capripoxvirus}

Partial amino acid sequences of $P 32$ protein of Kurdistan LSDV and SPV were compared with Capripoxvirus sequences published in Genbank (Table 1). The homology between Kurdistan Capripoxvirus was $96-100 \%$. The results showed 15 variable amino acids from the first 100 amino acids. The GPV lineage had unique characteristic residues $26 \mathrm{G}, 48 \mathrm{~K}$ and $95 \mathrm{~V}$ compared with other Capripoxvirus strains 26D, 48N, and 95A, respectively. The LSDV had an exclusive $51 \mathrm{~F}$ amino acid residue as compared with $51 \mathrm{~L}$ in other Capripoxvirus isolates. The SPV lineage had an exclusive inserted 57D amino acid residue. SPV also showed L64F substitution compared with LSDV and GPV lineages. All Kurdistan LSDV isolates presented in this study shared the same amino acid residue with other LSDV strains except for LSDV/2/Slemani/Kurdistan/2014 isolate accession No. (KM047051) that showed amino acid L51F substitution. There were only two amino acid substitutions in Kurdistan SPV isolates as compared with other Capripoxvirus strains - D18E in strains with accession No. (KP313625) and D46H in strains with accession No (KP313624).

\section{DISCUSSION}

In Iraq, the Capripoxvirus was isolated for the first time in Kurdistan, the northern part of Iraq and identified as GPV Sersenik strain (Tantawi \& Al Falluji, 1979). Sheep pox and goat pox are endemic in Iraq (Zangana \& Abdullah, 2013). The first natural outbreaks of LSD occurred in Iraq in 2013 (Al-Salihi \& Hassan, 2015). In this study, molecular detection and phylogenic analysis of $\mathrm{Ca}$ pripoxvirus were performed in Sulaimani province in Kurdistan region of Iraq to analyse the genetic relationship with the other Capripoxvirus worldwide and to understand the epidemiology of the new LSDV outbreaks in Iraq. Several researches used the P32 gene to detect SPV and GPV because it contains a most significant antigenic determinant present in all species of Capripoxvirus genus (Heine et al., 1999; Tian et al., 2010). Nevertheless, in this study the P32 gene was used for identification of LSDV to detriment the validity of the primers to detect LSDV in cattle and to provide P32 gene sequence information in LSDV because there were limited data descriptions of $P 32$ gene in LSDV as compared to GPCR gene and $R P O 30$ gene in the Genbank (Zhou et al., 2012). The phylogenic analysis of the Capripoxvirus indicated three lineages; SPV, GPV, and LSDV. All Capripoxvirus isolates from sheep in this study clustered in SPV lineage. This outcome proved that SPV is host specific (Beard et al., 2010). This finding also indicates that despite communal herding of sheep and goat, there was no clinical pox infection in goats in the Sulaimani province in 2013-2014. 
Molecular characterisation of lumpy skin disease virus and sheeppox virus based on P32 gene

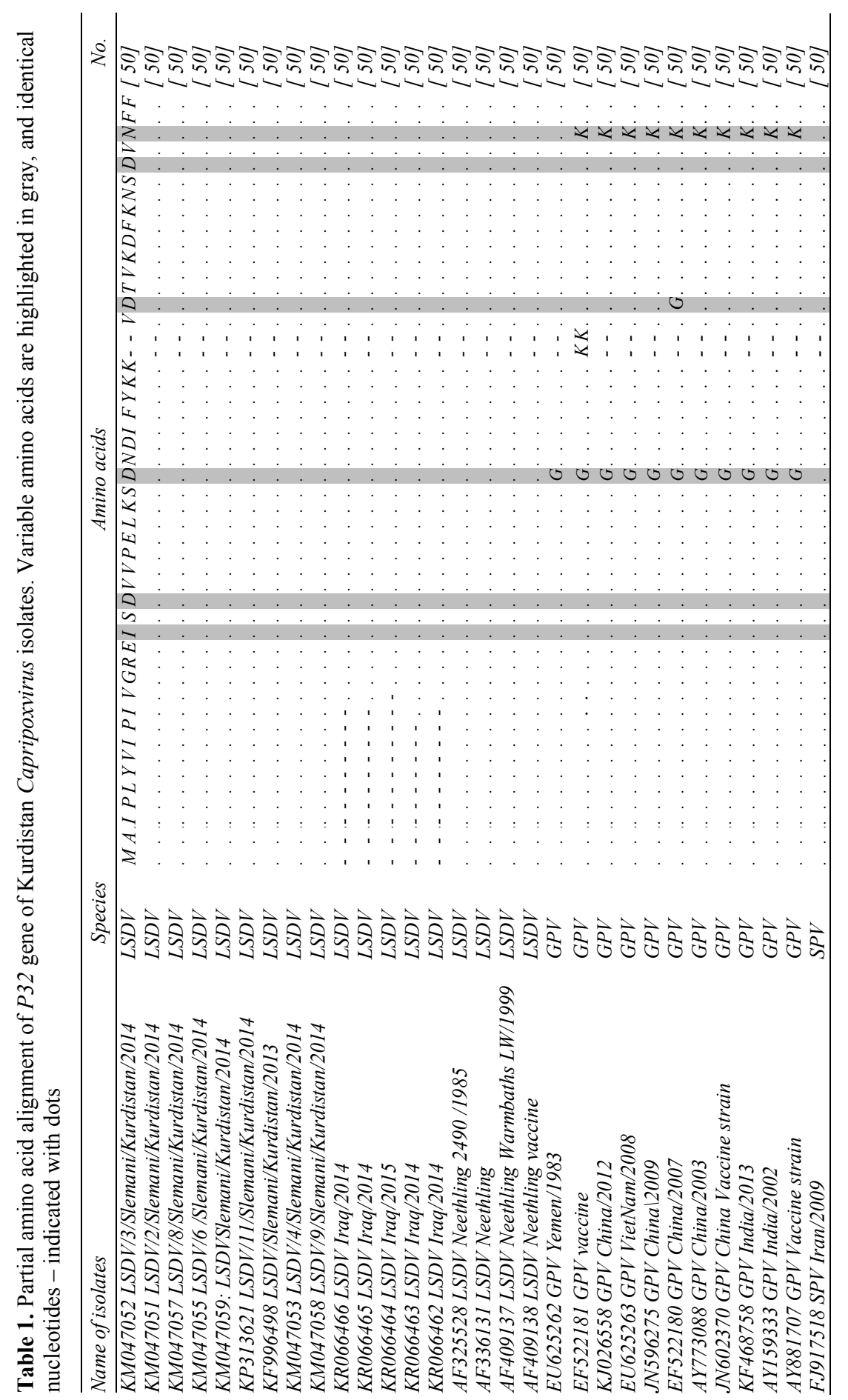




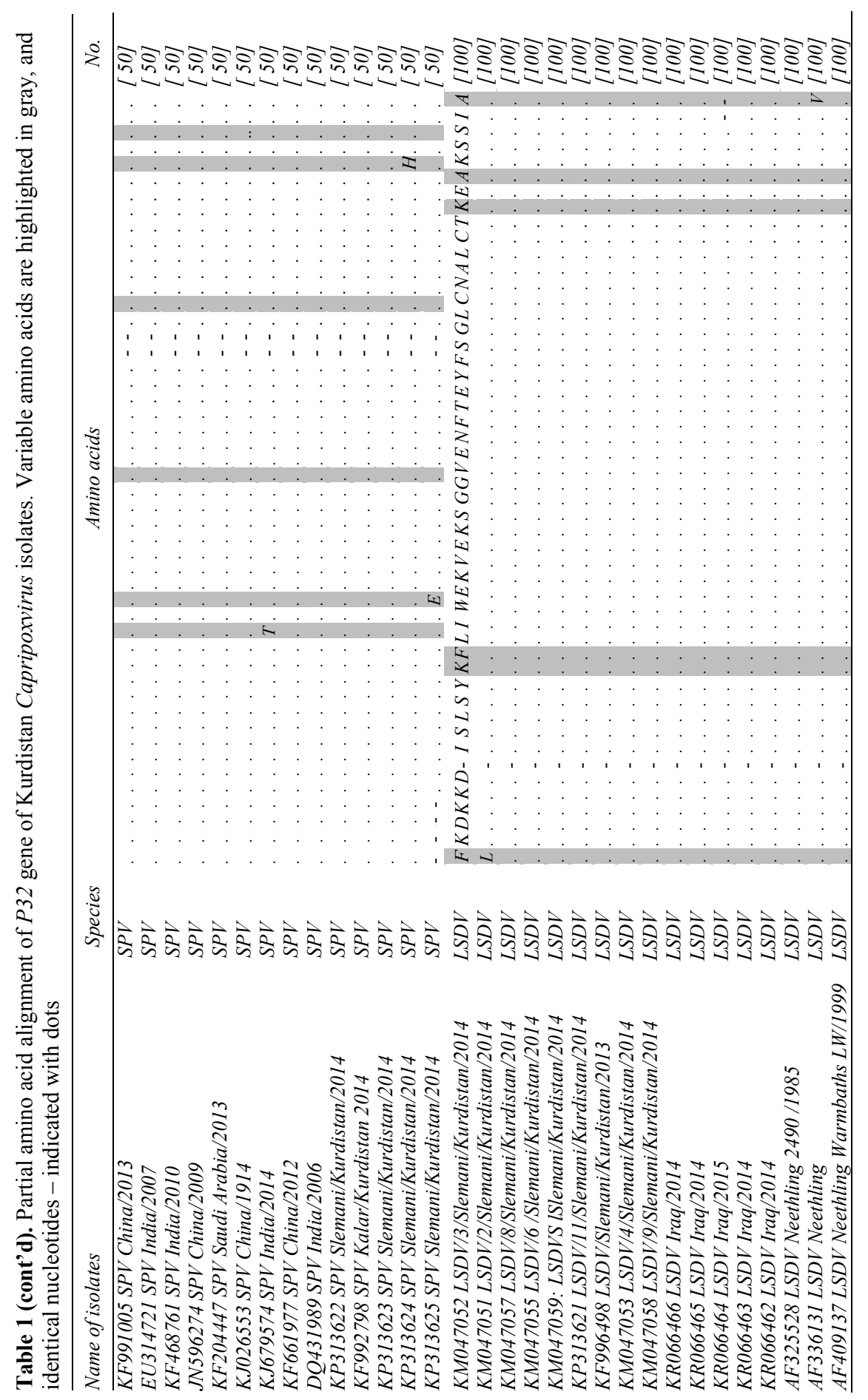

BJVM, 20, No 2 
Molecular characterisation of lumpy skin disease virus and sheeppox virus based on P32 gene




All Kurdistan LSDV isolates in this study clustered in LSDV lineage. However, LSDV/2/Slemani/Kurdistan/2014 isolate, accession No. (KM047051) is separated into a different sub cluster. LSDV/2/ Slemani/Kurdistan/2014 had an exclusive amino acid substitution L51F as compares to other LSDV in the Genebank. As the L51F substitution is the sequence characteristic for SPV, there may be new circulating LSDV isolates in Kurdistan. The homology between Kurdistan Capripoxvirus was $96-100 \%$. This finding justifies a previous publication that despite the close relationship between Capripoxvirus, they are phylogenetically distinct (Tulman et $a l .$, 2002). The topology of the phylogenetic tree based on amino acid sequence indicated that SPV and LSDV had a closer genetic relationship than goat GPV (Fig. 3). This result is similar to a phylogenetic analysis done by Beard et al. (2010). Conversely, the phylogenetic analysis based on nucleotide sequence of the same gene (P32) indicated that LSD and GPV had a closer genetic relationship than SPV (Zhu et al., 2013).

In conclusion, the $P 32$ gene is efficient for the detection and characterisation of LSDV. The analysis of the P32 genes of Kurdistan Capripoxvirus strains collected at different geographical locations in 2013-2014 suggests that few genetically distinct SPV circulated in the country. There may be a new LSDV isolate in Kurdistan which uniquely shared the same characteristic sequence of SPV at amino acid 51L in P32 gene. These findings provide new information on the epidemiology of Capripoxvirus in Iraq.

\section{ACKNOWLEDGEMENTS}

We would like to thank Sulaimani Veterinary Directorate for providing laboratory facilities.
Thanks also to all veterinary departments in Sulaimani Governorate.

\section{REFERENCES}

Al-Salihi, K. \& I. Hassan, 2015. Lumpy skin disease in Iraq: Study of the disease emergence. Transboundary and Emerging Diseases, 62, 457-462.

Beard, P., S. Sugar, E. Bazarragchaa, U. Gerelmaa, S. Tserendorj, E. Tuppurainen \& R. Sodnomdarjaa, 2010. A description of two outbreaks of capripoxvirus disease in Mongolia. Veterinary Microbiology, 142, 427-431.

Chand, P., R. Kitching \& D. Black, 1994 Western blot analysis of virus-specific antibody responses for capripox and contagious pustular dermatitis viral infections in sheep. Epidemiology and Infection, 113, 377-385.

Davies, F., 1991. Lumpy skin disease of cattle: A growing problem in Africa and the Near East. World Animal Review, 68, 37-42.

El-Nahas, E., A. El-Habbaa, G. El-Bagoury \& M. E. Radwan, 2011. Isolation and identification of lumpy skin disease virus from naturally infected buffaloes at Kaluobia, Egypt. Global Veterinaria, 7, 234-237.

Fauquet, C. M., M. A. Mayo, J. Maniloff, U. Desselberger \& L. A. Ball, 2005. Virus Taxonomy: VIII ${ }^{\text {th }}$ Report of the International Committee on Taxonomy of Viruses, Academic Press.

Fulzele, S., R. K., Singh, M. Hosamani, B. Mondal \& M. P. Yadav, 2006. Evaluation of duplex PCR and PCR-RFLP for diagnosis of sheep pox and goat pox. International Journal of Tropical Medicine, 1, 66-70.

Heine, H., M. Stevens, A. Foord \& D. Boyle, 1999. A capripoxvirus detection PCR and antibody ELISA based on the major antigen $\mathrm{P} 32$, the homolog of the vaccinia virus H3L gene. Journal of Immunological Methods, 227, 187-196. 
Kitching, R., 2000. OIE List A disease as a constraint to international trade. Annals of the New York Academy of Sciences, 916, 50-54.

Murphy, F. A., E. P. J. Gibbs, M. C.Horzinek \& M. J. Studdert, 1999. Veterinary Virology, $3^{\text {rd }}$ edn, Academic Press, San Diego.

Tantawi, H. \& M. Al Falluji, 1979. Laboratory characteristics of four strains of goatpox virus. Acta Virologica, 23, 455-460.

Thompson, J. D., D. G. Higgins \& T. J. Gibson, 1994. CLUSTAL W: Improving the sensitivity of progressive multiple sequence alignment through sequence weighting, position-specific gap penalties and weight matrix choice. Nucleic Acids Research, 22, 4673-4680.

Tian, H., Y. Chen, J. Wu, Y. Shang \& X. Liu, 2010. Serodiagnosis of sheeppox and goatpox using an indirect ELISA based on synthetic peptide targeting for the major antigen P32. Virology Journal, 7, 245.

Tulman, E., C. Afonso, Z. Lu, L. Zsak, J.-H. Sur, N. Sandybaev, U. Kerembekova, V. Zaitsev, G. Kutish \& D. Rock, 2002. The genomes of sheeppox and goatpox viruses. Journal of Virology, 76, 6054-6061.

Tuppurainen, E. \& C. Oura, 2012. Review: Lumpy skin disease: An emerging threat to Europe, the Middle East and Asia. Transboundary and Emerging Diseases, 59, 4048.
Zangana, I. \& M. Abdullah, 2013. Epidemiological, clinical and histopathological studies of lamb and kid pox in Duhok, Iraq. Bulgarian Journal of Veterinary Medicine, 16, 133-138.

Zhou, T., H. Jia, G, Chen, X. He, Y. Fang, X. Wang, Q. Guan, S. Zeng, Q. Cui \& Z. Jing, 2012. Phylogenetic analysis of Chinese sheeppox and goatpox virus isolates. Virology Journal, 9, 25.

Zhu, X., F. Yang, H. Li, Y. Dou, X. Meng, H. Li, X. Luo \& X. Cai, 2013. Identification and phylogenetic analysis of a sheep pox virus isolated from the Ningxia Hui Autonomous Region of China. Genetics and Molecular Research, 12, 1670-1678.

Paper received 15.12.2015; accepted for publication 08.04.2016

\section{Correspondence:}

Dr. Peshnyar M. A. Rashid

Molecular Diagnostic Laboratory, Sulaimani Veterinary Directorate, Slemani, Iraq 